\title{
Hearing Outcome of Low-tone Compared to High-tone Sudden Sensorineural Hearing Loss
}

\author{
George Psillas ${ }^{1}$ Aikaterini Rizou ${ }^{1} \quad$ Dimitrios Rachovitsas $^{1}$ Gabriel Tsiropoulos ${ }^{1}$ Jiannis Constantinidis ${ }^{1}$ \\ 1 1st Academic ENT Department, Aristotle University of Thessaloniki, \\ AHEPA Hospital, Thessaloniki, Greece \\ Address for correspondence Dr George Psillas, MD, 1st Academic ENT \\ Department, Aristotle University of Thessaloniki, AHEPA Hospital, 1, \\ Int Arch Otorhinolaryngol 2019;23:65-69. \\ Stilponos Kyriakidi St., GR 54636 Thessaloniki, Greece \\ (e-mail: psill@otenet.gr).
}

\begin{abstract}
Keywords

Introduction Low-tone sudden sensorineural hearing loss (SSHL) is a well-recognized disease, in which the hearing loss is restricted to low frequencies. In contrast to lowtone SSHL, high-tone SSHL is characterized by high-frequency $(4,000,8,000 \mathrm{~Hz})$ hearing loss and preservation of low-, middle-frequency hearing.

Objective The objective of this study is to compare the hearing recovery and longterm outcome of low-tone SSHL with those of patients affected by high-tone SSHL in a follow-up of $\sim 3$ years.

Methods The low-tone SSHL and high-tone SSHL groups included 27 and 20 patients, respectively; the patients of both groups were treated with intravenous steroids. Predictive factors (gender, affected side, delay of treatment, follow-up time) were also examined.

Results Overall, complete hearing recovery was observed in $77.7 \%$ of the patients in the low-tone SSHL group and in 15\% of the patients in the high-tone SSHL group. In the high-tone SSHL group, a higher proportion of patients reported tinnitus compared with the low-tone SSHL group (13 cases [65\%] versus 3 cases [11\%]); however, recurrences were more common in the low-tone SSHL (22\%, 6 patients) compared with the hightone SSHL (2 cases [10\%]) group. No predictive factor was found to statistically impact on hearing outcome.

- sudden hearing loss

- low tone

Conclusion After initial therapy, the low-tone SSHL patients have more favorable hearing outcome than high-tone SSHL patients. However, recurrences occurred more frequently in the low-tone SSHL group, while the high-tone SSHL group was more often

- prognosis accompanied by residual symptoms, such as tinnitus.
\end{abstract}

\section{Introduction}

Low-tone sudden sensorineural hearing loss (SSHL) is an already known clinical entity, presenting with low-frequency hearing loss and preservation of high-tone hearing, without vertigo. ${ }^{1} \mathrm{Abe}^{2}$ described SSHL as an independent disease after studying 39 patients in 1982. Since then, lowtone SSHL was often discussed in Japan and Korea, but less documented in the European or North American studies. The incidence of low-tone SSHL is estimated to be $\sim 40$ to 60 / 100,000 based on Japanese regional surveys. ${ }^{3}$

received

December 8, 2017

DOI https://doi.org/

accepted after revision

April 15, 2018

published online

June 19, 2018
On the other hand, high-tone SSHL has not been extensively studied so far, which is characterized by elevation of the thresholds in the high-frequency range and preservation of low-, middle-frequency hearing. In this study, we retrospectively reviewed the records of patients with the diagnosis of low-tone SSHL and compared their hearing thresholds outcome, hearing recovery and long-term symptoms with those of patients affected by high-tone SSHL. Predictive factors affecting the hearing outcome in a follow-up of $\sim 3$ years after treatment were also examined.

Copyright $\odot 2019$ by Thieme Revinter Publicações Ltda, Rio de Janeiro, Brazil 


\section{Methods}

The study sample consisted of 47 patients divided in 2 groups, the low-tone SSHL group (27 patients, 10 males, 17 females), and the high-tone SSHL group (20 patients, 8 males, 12 females). The patient characteristics of the two groups are summarized in - Table 1. Retrocochlear disease, otologic surgery, acoustic trauma (or barotrauma), acute or chronic otitis media and Ménière disease were excluded from this study.

Low-tone type SSHL was defined as the hearing loss for which the average from 3 low frequencies (125, 250, and 500 $\mathrm{Hz}$ ) was $\geq 30 \mathrm{~dB}$, and the average from 3 high frequencies $(2,000,4,000$ and $8,000 \mathrm{~Hz})$ was $\leq 20 \mathrm{~dB} .{ }^{4}$ High-tone SSHL was always associated with a sensation of loss of auditory acuity, tinnitus or ear fullness and was characterized by at least a 15-dB difference in hearing level at high frequencies $(4,000$ and/or $8,000 \mathrm{~Hz})$ in comparison with that of the healthy side; moreover, hearing thresholds at other frequencies were within the normal limits on the affected side.

All the patients were treated in our clinic with intravenous steroids (dexamethasone, $8 \mathrm{mg}, 3$ times daily and tapered every 3 days over 10 days). After discharge, the patients of the low-tone SSHL group were followed for a mean of 3.3 years (standard deviation [SD]: 2.9 years), and those of the hightone SSHL group for a mean of 2.8 years (SD:1.6 years).

The age, gender, affected side, delay of treatment and follow-up period were also statistically studied in relation to the hearing recovery in the two groups. To better study the effect of the time gap between the onset of sudden hearing loss and treatment, each group was divided into 2 subgroups, the early and the late; the early subgroup started the treatment within 2 days of SSHL onset, and the late subgroup, in which the treatment was delayed for more than 2 days of SSHL onset.

At the last follow-up, the final outcome in each group was recorded as follows: complete recovery: final hearing level within 0 to $20 \mathrm{~dB}$, or the average gain was $10 \mathrm{~dB}$ or less between 2 ears. Partial recovery: the average gain was improved $10 \mathrm{~dB}$ or more when compared with the initial audiogram. Unchanged: the final average gain was within 10 $\mathrm{dB}$. Moreover, each band of frequencies was statistically compared before and after the treatment, for the low-tone SSHL group $(125,250,500 \mathrm{~Hz})$ and for the high-tone SSHL group $(4,000$ and $8,000 \mathrm{~Hz}$, respectively). The patients were also asked to report on persistent tinnitus, possible recurrences of sudden hearing loss or episodes compatible with Ménière disease.

\section{Statistics}

The variables in this study included gender, age, affected side, follow-up period, hearing thresholds at each frequency pre and posttreatment, time gap between the onset of sudden hearing loss and the start of treatment.

Absolute and relative frequencies for all demographic and clinical variables were obtained. All variables were checked for normality via the Kolmogorov-Smirnov test. Non-parametric tests were used where applicable. Collinearity among scores and other variables in the study was assessed via a correlation matrix, using Pearson $r$ or Spearman $\rho$ correlation coefficient. The Student $t$-test or the Mann-Whitney U-test was used for independent sample comparisons. Paired $t$-test or paired Wilcoxon signed rank test was used for paired comparisons. Pearson Chi square was used for categorical comparisons. The Type I error probability associated with all tests in this study was set to 0.05 . The statistical analyses were performed using the IBM SPSS Statistics for Windows, version 23.0 package (IBM Corp., Armonk, NY, USA).

\section{Results}

The pattern of hearing levels (based on pure tone average at each frequency) of pre and posttreatment is illustrated in -Fig. 1 and $\mathbf{2}$ for the low-tone and high-tone SSHL groups, respectively. A very statistically significant improvement in hearing was found for all low frequencies $(125,250,500 \mathrm{~Hz})$ in the low-tone SSHL group (- Table 2). In the high-tone SSHL group, a significant hearing recovery was revealed at $4,000 \mathrm{~Hz}$; however, there was no improvement in hearing at $8,000 \mathrm{~Hz}$ (- Table 3 ).

According to - Table 4, at the final follow-up, the low-tone SSHL group showed better hearing outcome compared with the high-tone SSHL group. Complete hearing recovery was observed in $77.7 \%$ of patients of the low-tone SSHL group compared with $15 \%$ of cases of the high-tone SSHL group.

In our study, gender, age, affected side and follow-up period had no statistically significant impact on hearing outcome ( - Table 1); the earlier onset of treatment would possibly affect the hearing recovery in the low-tone group (statistical

Table 1 Patient characteristics with low- and high-tone sudden sensorineural hearing loss

\begin{tabular}{|l|l|l|l|l|l|}
\hline & $\begin{array}{l}\text { Gender } \\
\text { (males/females) }\end{array}$ & $\begin{array}{l}\text { Age } \\
\text { (range in years, } \\
\text { mean } \pm \text { SD) }\end{array}$ & $\begin{array}{l}\text { Side } \\
\text { (right/left) }\end{array}$ & $\begin{array}{l}\text { Delay of } \\
\text { treatment } \\
\text { (range in days, } \\
\text { mean } \pm \text { SD) }\end{array}$ & $\begin{array}{l}\text { Follow-up } \\
\text { (in years, } \\
\text { mean } \pm \text { SD) }\end{array}$ \\
\hline Low-tone $(n=27)$ & $10 / 17$ & $19-72,44.1 \pm 13.1$ & $13 / 14$ & $0-14 ; 2.7 \pm 3.3$ & $3.3 \pm 2.9$ \\
\hline High-tone $(n=20)$ & $8 / 12$ & $16-64,41.4 \pm 13.5$ & $11 / 9$ & $0-60 ; 8.6 \pm 14.2$ & $2.8 \pm 1.6$ \\
\hline Post-treatment & $p=0.537$ & $p=0.496$ & $p=0.433$ & $p=0.089$ & $p=0.947$ \\
\hline
\end{tabular}

Abbreviation: SD, standard deviation. 


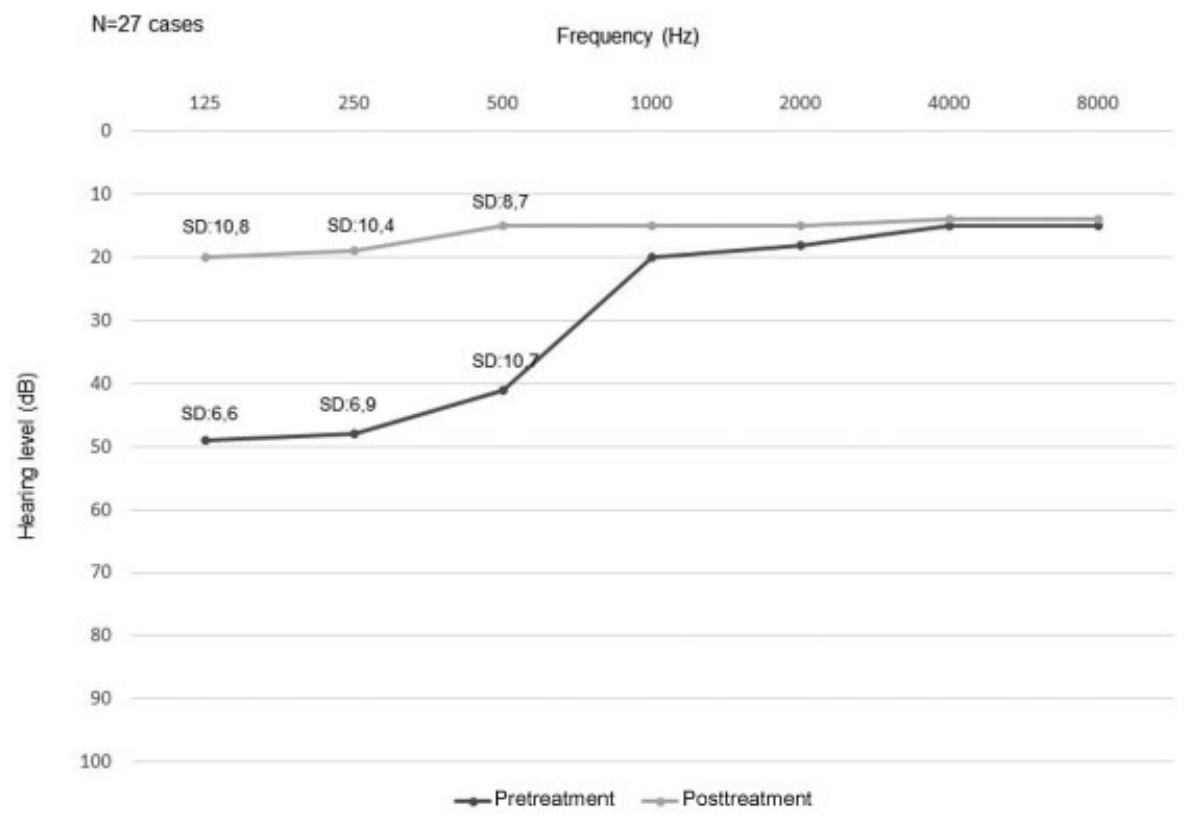

Fig. 1 Audiometric configuration of low-tone sudden sensorineural hearing loss based on average hearing thresholds, pre- and posttreatment, at each frequency (SD: standard deviation).

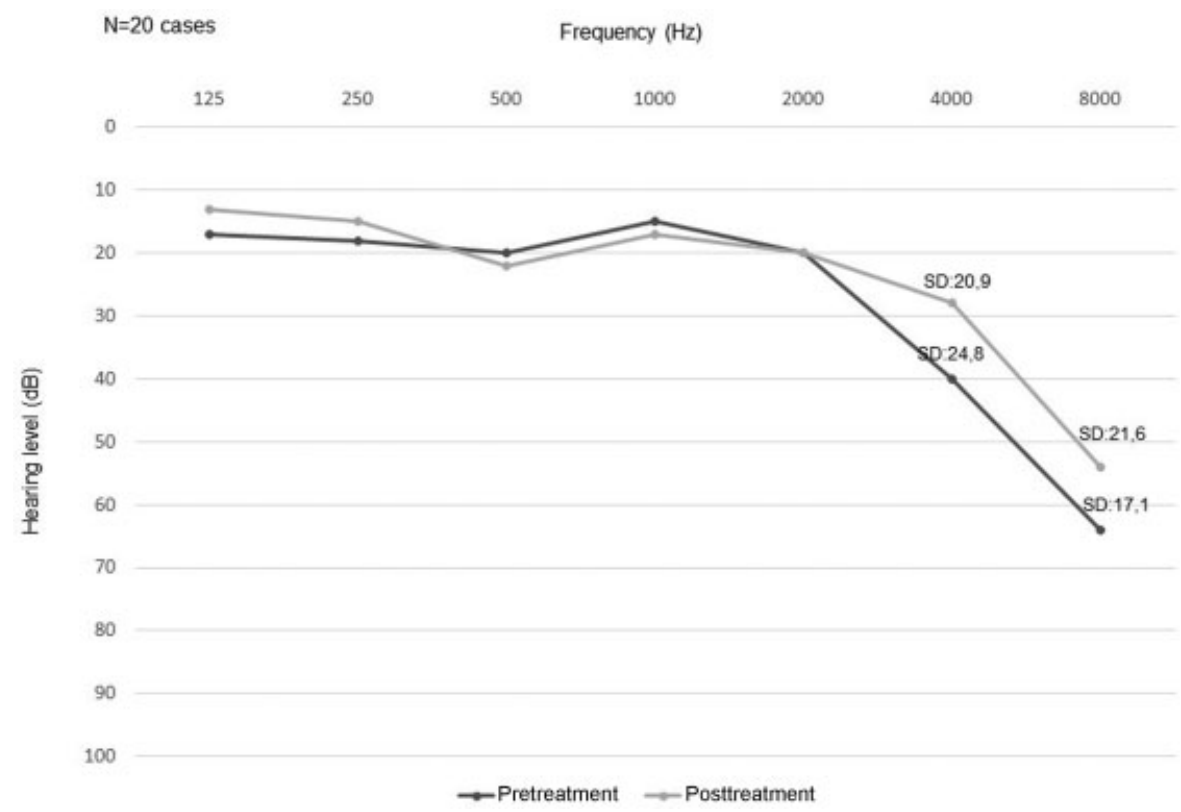

Fig. 2 Audiometric configuration of high-tone sudden sensorineural hearing loss based on average hearing thresholds, pre- and posttreatment, at each frequency (SD: standard deviation).

Table 2 Low-tone sudden sensorineural hearing loss group; pure tone audiogram average threshold by frequency $(\mathrm{dB} \mathrm{HL})$ pre and posttreatment

\begin{tabular}{|l|l|l|l|}
\hline $\mathrm{Hz}$ & Pre & Post & $p$ Value \\
\hline 125 & $49.44 \pm 6.699$ & $20.56 \pm 10.860$ & $<0.001$ \\
\hline 250 & $48.15 \pm 6.954$ & $19.26 \pm 10.442$ & $<0.001$ \\
\hline 500 & $41.48 \pm 10.725$ & $15.93 \pm 8.775$ & $<0.001$ \\
\hline
\end{tabular}

Table 3 High-tone sudden sensorineural hearing loss group; pure tone audiogram average threshold by frequency $(\mathrm{dB} \mathrm{HL})$ pre and posttreatment

\begin{tabular}{|l|l|l|l|}
\hline $\mathrm{Hz}$ & Pre & Post & $p$-value \\
\hline 4,000 & $40.00 \pm 24.815$ & $28.25 \pm 20.981$ & 0.016 \\
\hline 8,000 & $64.00 \pm 17.137$ & $54.75 \pm 21.611$ & 0.081 \\
\hline
\end{tabular}


Table 4 Hearing recovery at the last follow-up in low- and hightone sudden sensorineural hearing loss

\begin{tabular}{|l|l|l|l|}
\hline & Complete & Partial & Unchanged \\
\hline $\begin{array}{l}\text { Low-tone } \\
(n=27)\end{array}$ & $21(77.7 \%)$ & $3(11.1 \%)$ & $3(11.1 \%)$ \\
\hline $\begin{array}{l}\text { High-tone } \\
(n=20)\end{array}$ & $3(15 \%)$ & $6(30 \%)$ & $11(55 \%)$ \\
\hline
\end{tabular}

Note: The low-tone sudden sensorineural hearing loss group showed better hearing outcome compared with the high-tone sudden sensorineural hearing loss group (Pearson Chi-squared test, $p<0.001$ )

trend), but the same would not happen in the high-tone SSHL group. No statistically significant difference $(p=0.088)$ was found between the early and the late subgroup in both groups related to the time elapsed (less/more than 2 days) from the onset of hearing loss to the start of treatment.

At the last follow-up ( $\sim 3$ years) in the low-tone SSHL group, 3 (11\%) patients were still complaining of tinnitus, and another 6 (22\%) patients had recurrences of low-tone SSHL in the diseased ear, half of them in the first year of the first attack; Ménière disease occurred in the diseased ear of another 2 (7\%) patients at 1.5 and 10 years after SSHL onset, respectively. Overall, no complete relief from symptoms was reported in $40 \%$ (11 patients) of cases in the low-tone SSHL group.

Compared with the low-tone SSHL group, a higher proportion (15/20 cases, $75 \%$ ) of patients in the high-tone SSHL group reported persistent symptoms. From these, 13 (65\%) patients still had tinnitus in the diseased ear and another 2 patients suffered from 2 (10\%) recurrences; 1 patient experienced a 2nd episode of SSHL in the diseased ear 1 month later, and the other patient 3 years later. In this group, no patient experienced episodes compatible with Ménière disease.

\section{Discussion}

Most authors have already reported that the prognosis of low-tone SSHL (or upward-sloping audiogram) is better than that of high-tone SSHL (or downward-sloping audiogram), ${ }^{1,5}$ although this is not in agreement with other studies. ${ }^{6,7}$ In our study, high-tone SSHL was audiometrically defined as thresholds elevation restricted to high-frequencies, in contrast to low-tone SSHL. According to the results, patients with hearing loss in the high-frequency band clearly had poorer recovery rates than those with hearing loss in lowfrequency band (77.7\% versus $15 \%$ ). The symptoms in hightone SSHL were quite similar to those in low-tone SSHL, characterized by a sensation of loss of auditory acuity, tinnitus, autophony or fullness in the affected ear; moreover, female preponderance and peak incidence during the fourth decade of life ${ }^{8}$ seem to be common in these two clinical entities (-Table 1).

Our treatment for low-tone SSHL group was based on intravenous steroid with complete recovery of hearing in $77.7 \%$ of patients, which is comparable to the findings of other relatively recent studies. ${ }^{1,9}$ Jung et al $^{1}$ found an audiometric improvement rate of $76 \%$ with oral steroids alone (follow-up: 8 weeks), which was better than $50 \%$ achieved after intratympanic steroid injections alone and $76.9 \%$ with combination of the two methods. In a study with almost 2 years of follow-up, Roh et $\mathrm{al}^{9}$ demonstrated complete hearing improvement in 75\% of patients after treatment mainly with oral steroids, which was very close to the results obtained in our last follow-up. However, Morita et $\mathrm{al}^{10}$ showed lower recovery rates with oral steroid alone (63\%) but with 2 months follow-up. It has also been advocated that when diuretics were added to steroids the recovery rates are significantly improved (78.2\% to $83.9 \%)$. $4,10,11$

In high-tone SSHL, the hearing recovery was statistically significant after treatment at all frequencies, except at $8,000 \mathrm{~Hz}$ (-Table 3). We have no explanation why the treatment for high-tone SSHL is ineffective at $8,000 \mathrm{~Hz}$. It is possible that this region of cochlea at the end portion of the basal turn is most vulnerable to damage, reflecting the gradual downward-sloping hearing loss in presbycusis or ototoxicity with degradation of hearing thresholds at higher frequencies. It has been reported that the levels of glutathione, an antioxidant, tend to be lower at the most basal cochlear turn hair cells and inversely increasing toward the apex; ${ }^{12}$ glutathione peroxidase is an enzyme that alter reactive oxygen species to less damaging forms. ${ }^{12}$

The pathophysiologic mechanism of low-tone SSHL is still unclear. According to studies, the low-tone SSHL may be a variant of Ménière disease, or the beginning period of Ménière disease. ${ }^{1,13}$ Yamasoba et al, ${ }^{14}$ using glycerol test and electrocochleogram (elevated SP/AP ratio), suggested that low-tone SSHL might be caused by endolymphatic hydrops. Fuse et $\mathrm{al}^{15}$ reported that the etiology of lowtone SSHL involves an autoimmune response of the endolymphatic sac that induces endolymphatic hydrops. On the other side, Choi et al ${ }^{11}$ supported that low-tone SSHL might be a different disease entity from Ménière disease, since only 1 among 18 patients who had been checked with electrocochleogram during acute low-tone SSHL showed elevated SP/ AP ratio. Moreover, $\mathrm{Wu}$ and Young ${ }^{16}$ demonstrated that lowtone SSHL should be differentiated from Ménière disease on the basis of vestibular evoked myogenic potentials (VEMPs), since most patients with low-tone SSHL revealed normal VEMPs; in contrast, $50 \%$ of Ménière disease patients with low-tone hearing loss showed abnormal VEMPs. In our study, low-tone SSHL progressed to Ménière disease in only 2 (2/27, 7\%) patients at 1.5 and 10 years after the SSHL onset. Similarly, Yamasoba et $\mathrm{al}^{14}$ reported that $5(11 \%)$ out of 45 patients followed up for more than 3 years developed Ménière disease. Compared with low-tone SSHL cases, our patients with high-tone SSHL did not develop Ménière disease, although initially there were a few complaints of lightheadedness and instability. It seems that low-tone SSHL is not the same disease as Ménière disease because a limited proportion of low-tone SSHL cases progressed to Ménière disease.

However, recurrences occurred more frequently in the low-tone SSHL (22\%) than in the high-tone SSHL group (10\%). It has been postulated ${ }^{17}$ that patients with low-tone SSHL 
suffering of recurrent episodes of hearing loss tended to have endolymphatic hydrops (higher summation potential/action potential [SP/AP] ratio of electrocochleography), whereas those without recurrent episodes do not. According to previous reports, ${ }^{1,3,9,14}$ the incidence of recurrences after lowtone SSHL onset has ranged from 9 to $45 \%$, the majority of them were documented within one year of the first attack., Indeed, Oishi et $\mathrm{al}^{5}$ supported that if the low-tone SSHL patients display hearing fluctuations within one year after the initial attack, about half of them exhibited high- and panfrequency hearing loss within 10 years of onset; nevertheless, with regard to progression of hearing loss at high frequencies we should consider the effect of aging.

In both groups, no factors such as gender, age, affected side, follow-up period, hearing thresholds at each frequency pre and posttreatment have been found to be significant in prognosis. The earlier onset of treatment would possibly affect the hearing recovery in the low-tone SSHL group (statistical trend). In addition, a prompt treatment with steroids within 2 days from the onset of low- or high-tone SSHL was not apparently related to the final hearing outcome. However, it has been advocated that age, ${ }^{11}$ co-occurrence of tinnitus, ${ }^{1}$ degree of pretreatment hearing loss on the affected side ${ }^{1}$ and time interval between onset and start of treatment ${ }^{11}$ are positive prognostic factors of hearing recovery in low-tone SSHL.

\section{Conclusion}

High-tone SSHL, which is characterized by hearing loss at high frequencies, shows poor recovery rates and residual symptoms, such as tinnitus; low-tone SSHL has a more favorable hearing outcome but is more often associated with recurrences and less commonly progressed to Ménière disease. Further studies are needed, as well as more extensive research, to better understand the etiology of both lowand high-tone SSHL.

\section{References}

1 Jung AR, Kim MG, Kim SS, Kim SH, Yeo SG. Clinical characteristics and prognosis of low frequency sensorineural hearing loss without vertigo. Acta Otolaryngol 2016;136(02):159-163
2 Abe T. Acute sensorineural hearing loss in low tone frequencies. Otolaryngology (Tokyo) 1982;54:385-392

3 Fushiki H, Junicho M, Aso S, Watanabe Y. Recurrence rate of idiopathic sudden low-tone sensorineural hearing loss without vertigo: a long-term follow-up study. Otol Neurotol 2009;30(03):295-298

4 Im GJ, Kim SK, Choi J, Song JJ, Chae SW, Jung HH. Analysis of audiovestibular assessment in acute low-tone hearing loss. Acta Otolaryngol 2016;136(07):649-654

5 Oishi N, Inoue Y, Saito H, Kanzaki S, Kanzaki J, Ogawa K. Long-term prognosis of low-frequency hearing loss and predictive factors for the 10-year outcome. Otolaryngol Head Neck Surg 2010;142(04): 565-569

6 Edizer DT, Çelebi Ö, Hamit B, Baki A, Yiğit Ö. Recovery of idiopathic sudden sensorineural hearing loss. J Int Adv Otol 2015;11(02): 122-126

7 Narozny W, Kuczkowski J, Kot J, Stankiewicz C, Sicko Z, Mikaszewski B. Prognostic factors in sudden sensorineural hearing loss: our experience and a review of the literature. Ann Otol Rhinol Laryngol 2006;115(07):553-558

8 Imamura S, Nozawa I, Imamura M, Murakami Y. Clinical observations on acute low-tone sensorineural hearing loss. Survey and analysis of 137 patients. Ann Otol Rhinol Laryngol 1997;106(09): $746-750$

9 Roh KJ, Lee EJ, Park AY, Choi BI, Son EJ. Long-term outcomes of acute low-tone hearing loss. J Audiol Otol 2015;19(02):74-78

10 Morita S, Suzuki M, Iizuka K. A comparison of the short-term outcome in patients with acute low-tone sensorineural hearing loss. ORL J Otorhinolaryngol Relat Spec 2010;72(06):295-299

11 Choi HG, Park KH, Seo JH, Kim DK, Yeo SW, Park SN. Clinical and audiologic characteristics of acute low-tone sensorineural hearing loss: therapeutic response and prognosis. Korean J Audiol 2011;15:8-13

12 Wong AC, Ryan AF. Mechanisms of sensorineural cell damage, death and survival in the cochlea. Front Aging Neurosci 2015;7:58

13 Noguchi Y, Nishida H, Tokano H, Kawashima Y, Kitamura K. Comparison of acute low-tone sensorineural hearing loss versus Meniere's disease by electrocochleography. Ann Otol Rhinol Laryngol 2004;113(3 Pt 1):194-199

14 Yamasoba T, Kikuchi S, Sugasawa M, Yagi M, Harada T. Acute lowtone sensorineural hearing loss without vertigo. Arch Otolaryngol Head Neck Surg 1994;120(05):532-535

15 Fuse T, Hayashi T, Oota N, et al. Immunological responses in acute low-tone sensorineural hearing loss and Ménière's disease. Acta Otolaryngol 2003;123(01):26-31

$16 \mathrm{Wu}$ CL, Young YH. Vestibular evoked myogenic potentials in acute low-tone sensorineural hearing loss. Laryngoscope 2004;114 (12):2172-2175

17 Junicho M, Aso S, Fujisaka M, Watanabe Y. Prognosis of low-tone sudden deafness - does it inevitably progress to Meniere's disease? Acta Otolaryngol 2008;128(03):304-308 